\title{
Rantai Pasok Brokoli di Kecamatan Lembang Kabupaten Bandung Barat dengan Pendekatan Food Supply Chain Networks
}

\section{Supply Chain of Broccoli in Lembang, West Bandung District with Food Supply Chain Networks Approach}

\author{
Clara Yolandika ${ }^{1)}$, Rita Nurmalina $^{2)}$, dan Suharno ${ }^{2)}$ \\ ${ }^{1}$ Mahasiswa Magister Sains Agribisnis Institut Pertanian Bogor \\ ${ }^{2}$ Staff Pengajar Magister Sains Agribisnis Institut Pertanian Bogor \\ Jalan Raya Darmaga, Bogor, Jawa Barat 16680 \\ e-mail : clarayolandika@gmail.com
}

\begin{abstract}
This study aims to determine the condition of the supply chain broccoli in the district of Bandung Lembang district west to approach food supply chain networks ( FSCN ). This research will be carried out in the $C V$. Yan's Fruits and Vegetable in Lembang district, West Bandung regency, West Java. This study requires an approach to qualitative and quantitative methods for treating primary and secondary data. To analyze the supply chain qualitative and quantitative data required by the framework of the Food Supply Chain Networking (FSCN) of Lambert and Cooper (2000) as modified by Vorst (2006). Results from this study is the condition of supply chain broccoli in Lembang district West Bandung regency based approach is the Food Supply Chain Networks as seen from the target supply chain, the structure of the supply chain, the entity supply chain, supply chain management, resource supply chain, and business processes of supply chain is already integrated well.
\end{abstract}

Keywords: Broccoli, FSCN, Supply Chain

Diterima : 02 Juli 2016, disetujui 30 Agustus 2016

\section{PENDAHULUAN}

Perubahan pola hidup pada umumnya terjadi pada masyarakat yang hidup di kota besar dengan tingkat ekonomi menengah dan menengah ke atas. Salah satu perubahan yang cukup signifikan adalah mulai beralihnya pola konsumsi masyarakat dari mengkonsumsi sayuran yang berkadar gizi rendah menjadi sayuran berkualitas dan berkadar gizi tinggi, terutama brokoli. Namun, terdapat beberapa kendala dalam usaha memenuhi permintaan sayuran yang berkualitas tersebut, diantaranya kurangnya pengetahuan petani mengenai system penanaman yang tepat.

Menurut Direktorat Jenderal Hortikultura (2014), permintaan brokoli di Indonesia cenderung mengalami peningkatan. Hal ini menunjukkan brokoli memiliki potensi untuk dikembangkan dan dapat membantu memajukan pertanian Indonesia karena permintaan yang tinggi dari pasar dalam negeri. Data konsumsi brokoli per kapita dari Susenas (2015) menunjukkan bahwa konsumsi brokoli mengalami peningkatan setiap tahun. Peningkatan konsumsi menunjukkan terjadinya peningkatan permintaan brokoli dalam negeri, terutama di kota-kota besar, sehingga diperlukan perlakuan khusus mulai dari subsistem hulu hingga hilir agar kesegaran dan kesehatan produk tetap terjaga ketika sampai di tangan konsumen akhir. 


\section{Jurnal Penelitian Pertanian Terapan}

Upaya meningkatkan produksi, produktivitas, mutu, dan daya saing secara optimal, diperlukan penanganan yang efektif dan efisien antar aspek produksi dan distribusi. Salah satu kegiatan prioritas yang telah disusun oleh Direktorat Jenderal Hortikultura yang terdapat dalam "Enam Pilar Kegiatan Pengembangan Hortikultura Tahun 2012" untuk memperbaiki pemasaran produk hortikultura adalah dengan mengaplikasikan manajemen rantai pasok.

\section{METODE}

Penelitian ini akan dilaksanakan di CV. Yan's Fruits and Vegetable di Kecamatan Lembang, Kabupaten Bandung Barat, Jawa Barat. Pemilihan lokasi penelitian dilakukan secara sengaja (purposive sampling) berdasarkan pertimbangan kondisi wilayah penelitian yang merupakan salah satu sentra sayuran di Jawa Barat dan keadaan alamnya cocok untuk budidaya brokoli, adanya kerjasama mitra dengan beberapa petani mitra brokoli terutama di wilayah Jakarta sekitarnya, serta terdapat permasalahan gap antara jumlah permintaan pasar dengan jumlah sayuran oleh petani mitra kepada perusahaan.

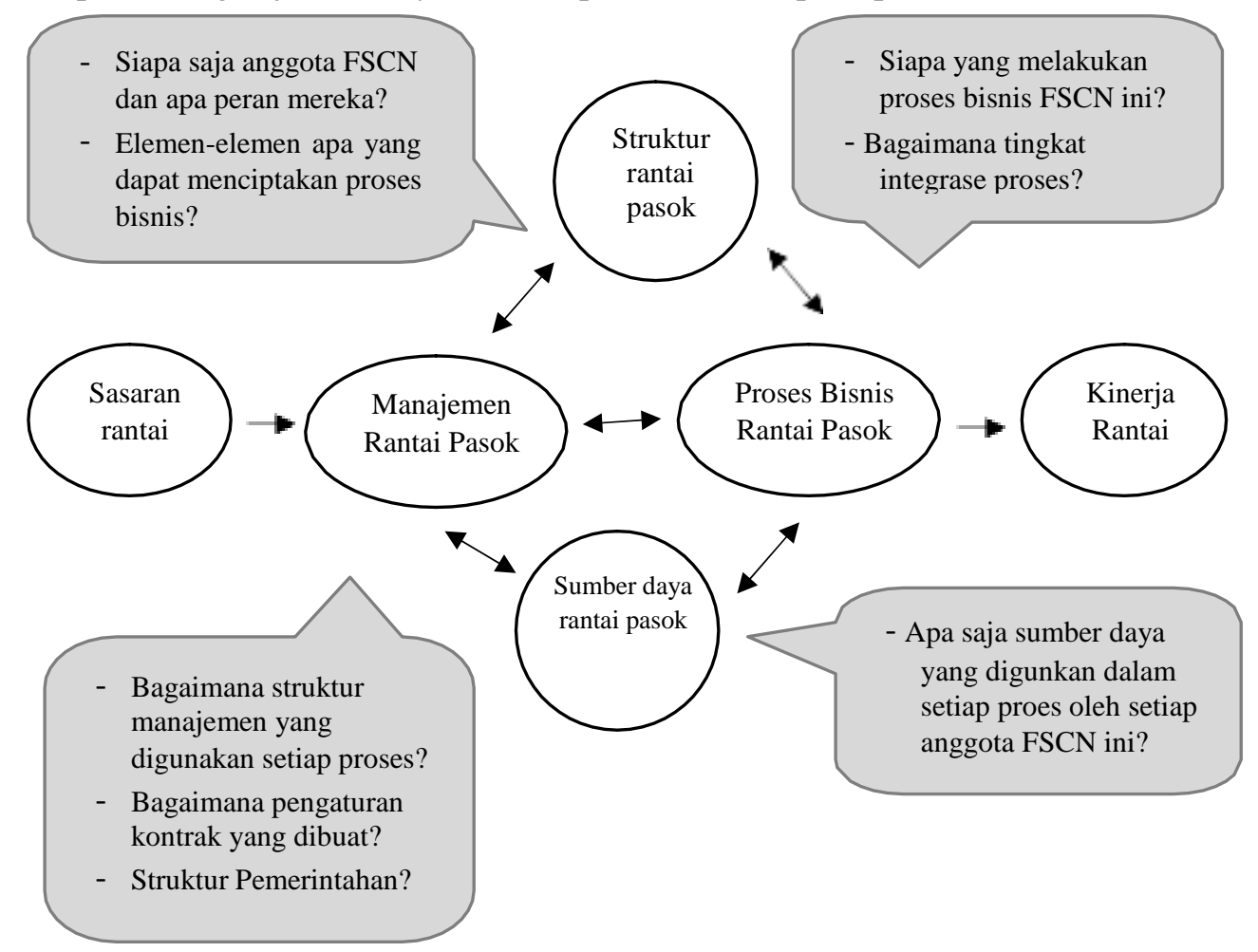

Gambar 1. Kerangka Analisis Deskriptif Rantai Pasok (Van der Vorst (2006))

Penelitian ini membutuhkan pendekatan metode kualitatif dan kuantitatif untuk mengolah data primer dan sekunder. Untuk menganalisis rantai pasok diperlukan data kualitatif dan kuantitatif. Data kualitatif dilakukan secara deskriptif sesuai dengan kerangka Food Supply Chain Networking (FSCN) dari Lambert dan Cooper (2000) yang dimodifikasi oleh Vorst (2006) yang dapat dilihat pada Gambar 1.

\section{HASIL DAN PEMBAHASAN}

\section{Sasaran Rantai Pasok}

Sasaran pasar. Sasaran pasar dapat dilihat dari upaya segmentasi pasar, kualitas yang terintegrasi, dan optimalisasi rantai. Segmentasi pasar brokoli yang ditetapkan perusahaan adalah kalangan menengah dan menengah ke atas yang telah menyadari pentingnya hidup sehat. Harga jual yang ditetapkan perusahaan 
untuk brokoli termasuk menengah ke atas karena melihat pasar ritel yang menjadi mitra perusahaan telah memperoleh kepercayaan besar dari konsumen. Jika dibandingkan dengan harga brokoli biasa, harga brokoli lebih mahal karena terdapat image sehat yang menjadi aspek yang dijual dalam produk ini.

Sasaran pengembangan. Sasaran pengembangan yang ingin dicapai rantai pasok brokoli pada CV. Yan's Fruits and Vegetable adalah penguatan rantai pasok dengan cara pelaksanaan kemitraan yang berkesinambungan. Kerjasama kemitraan ataupun koordinasi lainnya yang melibatkan petani mitra, CV. Yan's Fruits and Vegetable, pihak ritel serta beberapa institusi pendukung diarahkan kepada perbaikan dan peningkatan kualitas, kuantitas, dan kontinuitas produk, dan pengembangan serta perbaikan infrastruktur.

\section{Struktur Rantai Pasok}

Anggota primer rantai pasok. Anggota primer pada rantai pasokan komoditas brokoli adalah petani brokoli mitra sebagai pemasok, perusahaan atau CV. Yan's Fruits and Vegetable sebagai pengolah (pengemasan), dan ritel (supermarket) sebagai konsumen. Koordinasi antar anggota didasari oleh kesadaran bahwa kuatnya rantai pasok tergantung pada kekuatan seluruh elemen yang ada di dalamnya.

Anggota sekunder rantai pasok. Anggota sekunder adalah pihak yang memperlancar kegiatan rantai pasok dalam menyediakan bahan baku yang dibutuhkan mulai dari kebutuhan budidaya, pengemasan sampai kebutuhan kantor. Bahan baku untuk budidaya meliputi benih, pupuk, pestisida, dan peralatan pertanian untuk petani mitra. Bahan baku untuk pengemasan yang dibutuhkan yaitu bahan pengemasan seperti: wrafing film, fresh vegetable tape, dan label. Hubungan CV. Yan's Fruit and Vegetable dengan beberapa pemasok bahan non sayur adalah hubungan sebagai konsumen biasa atau tidak ada hubungan jangka pendek dan jangka panjang. Sistem pembayaran yang dilakukan CV. Yan's Fruit and Vegetable dengan cara membayarnya setelah 1 bulan barang tersebut sampai di perusahaan.

Divisi di CV. Yan's Fruits and Vegetable mengajukan permohonan bahan baku non sayur ke divisi pengadaan

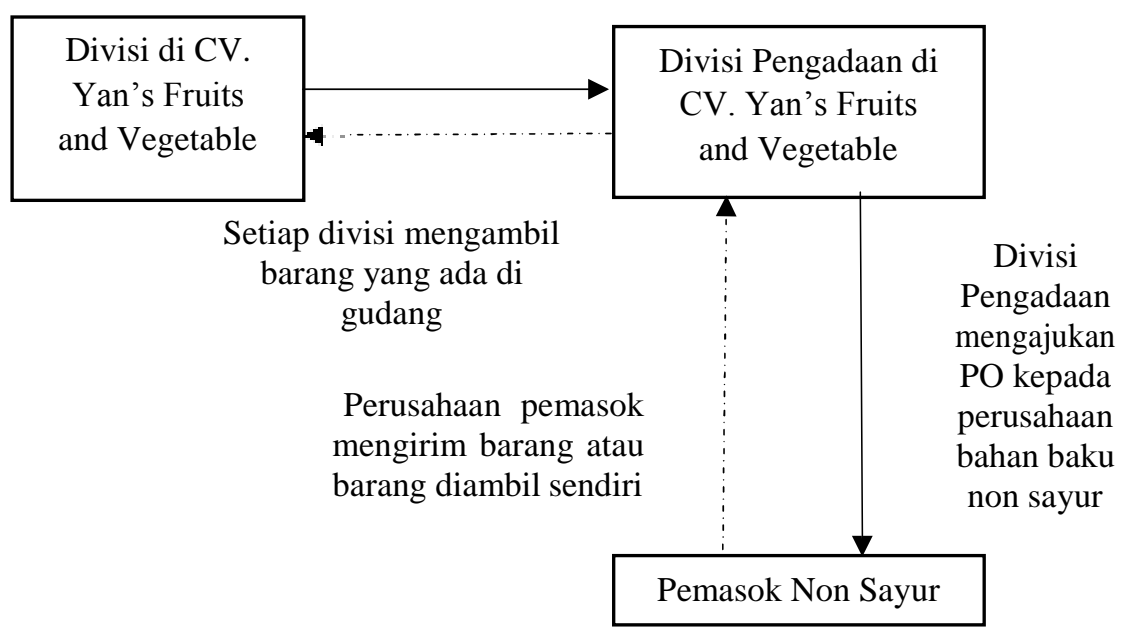

Gambar 2. Prosedur Pengadaan Kebutuhan Non Sayur

Pola aliran dalam rantai pasok. Menurut Pujawan (2005), pada suatu rantai pasok biasanya ada tiga macam aliran yang harus dikelola. Pertama aliran barang yang mengalir dari hulu (upstream) ke hilir (downstream). Kedua aliran uang (finansial) yang mengalir dari hilir ke hulu. Ketiga adalah aliran informasi yang bisa terjadi dari hulu ke hilir atau sebaliknya. Model rantai pasok pada komoditas brokoli terdiri atas petani, perusahaan, dan ritel. Gambar 3 menunjukkan pola aliran dalam rantai pasok brokoli. 


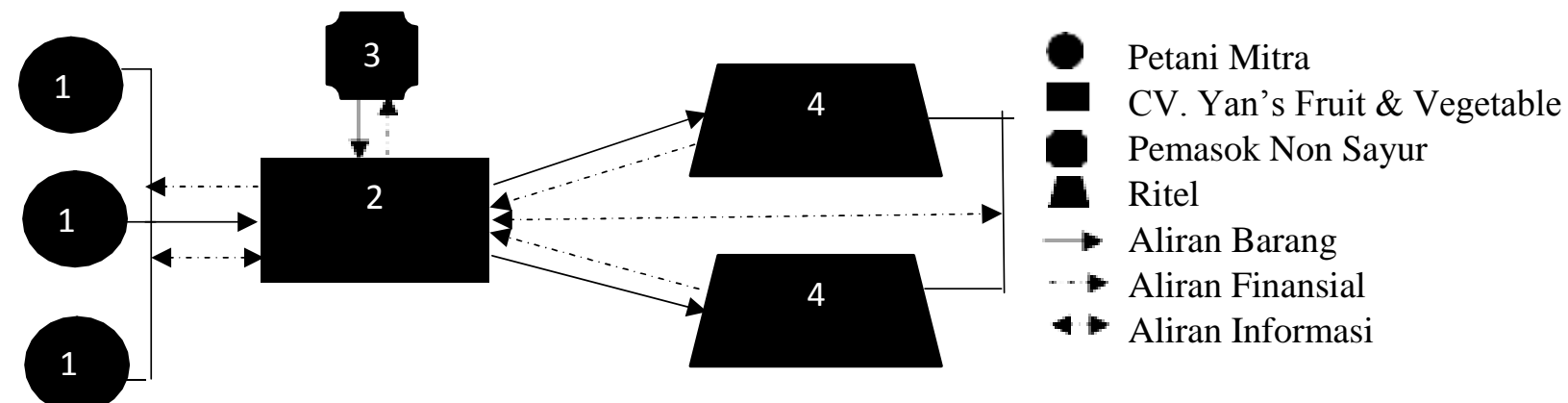

Gambar 3. Pola Aliran Rantai Pasok Brokoli

Aliran finansial pada rantai pasokan lettuce head terjadi dari ritel, CV. Yan's Fruits and Vegetable, dan petani. Ritel membayar secara kredit kepada perusahaan yang dibayarkan setelah dua minggu komoditas tersebut dikirimkan. Petani akan menerima pembayaran dari CV. Yan's Fruits and Vegetable sesuai dengan jumlah hasil panen yang telah disortasi. Pembayaran CV. Yan's Fruits and Vegetable kepada petani dilakukan setelah CV. Yan's Fruits and Vegetable menerima pembayaran dari ritel, artinya petani seperti memberikan modal terlebih dahulu kepada CV. Yan's Fruits and Vegetable.

\section{Manajemen Rantai Pasok}

Struktur manajemen. CV. Yan's Fruits and Vegetable membeli hasil panen brokoli dari petani mitra, perusahaan melakukan proses sortasi, grading, pengemasan, pelabelan, serta pengiriman brokoli kepada ritel. Struktur organisasi CV. Yan's Fruits and Vegetable sudah mempunyai suatu divisi khusus yang menangani masalah distribusi, sehingga masalah distribusi dapat diatasi dengan baik. Selain itu, CV. Yan's Fruits and Vegetable juga sudah memiliki divisi khusus dalam hal pengadaan bahan baku sayur dan non sayur secara khusus, sehingga proses pengadaan sudah berjalan dengan baik. Perencanaan dan strategi yang baik dibutuhkan untuk mendukung kegiatan rantai pasok, sehingga akan menghasilkan optimalisasi rantai pasok.

Kemitraan. Petani brokoli tidak memiliki kriteria khusus pemilihan mitra untuk memasarkan hasil panennya. Petani mitra mengandalkan kepercayaan terhadap CV. Yan's Fruits and Vegetable, dimana petani mitra memberikan modal sayuran kepada CV. Yan's Fruits and Vegetable dan bersedia dibayar dua minggu setelah syuran diterima oleh CV. Yan's Fruits and Vegetable. Kepercayaan muncul karena adanya saling membutuhkan dan menguntungkan di antara kedua belah pihak. Keuntungan yang didapat petani mitra setelah bergabung dengan CV. Yan's Fruits and Vegetable adalah harga jual yang stabil, posisi tawar dapat meningkat dibandingkan dengan memasarkan sendiri produknya ke pasar tradisional, dan perusahaan mampu membayar secara tunai dan tepat waktu sesuai dengan waktu yang telah disepakati. Ketika harga brokoli di pasar naik secara signifikan, perusahaan juga akan menaikkan harga beli brokoli dari petani. Hal ini dilakukan untuk menjaga hubungan baik dengan petani mitra dan menahan petani agar dapat terus loyal kepada CV. Yan's Fruits and Vegetable.

CV. Yan's Fruits and Vegetable juga memiliki kriteria dalam memilih mitra pemasar atau ritel yaitu penentuan harga brokoli yang menguntungkan, transparansi informasi pasar, komitmen kerjasama dalam jangka waktu yang lama, dan birokrasi tidak berbelit-belit. Penentuan harga brokoli dan transparansi informasi pasar bertujuan untuk menjaga posisi tawar. Komitmen kerjasama dilakukan untuk membentuk kemitraan yang berkesinambungan, sehingga kerjasama yang menguntungkan tetap terjaga. Birokrasi yang tidak berbelit-belit betujuan agar saat kegiatan transaksi sayuran dilakukan, tidak memakan waktu yang lama karena dalam satu hari CV. Yan's Fruits and Vegetable harus memasok sayuran ke beberapa ritel di lokasi yang berbeda-beda.

Kesepakatan kontraktual. Kesepakatan kontraktual yang digunakan oleh CV. Yan's Fruits and Vegetable kepada petani mitra yaitu petani mitra wajib memasok brokoli sesuai dengan kualitas dan 158 Volume 16, Nomor 3, September 2016 
kuantitas yang telah ditentukan oleh CV. Yan's Fruits and Vegetable. Sedangkan kesepakatan antara mitra tani dengan CV. Yan's Fruits and Vegetableadalah CV. Yan's Fruits and Vegetable wajib membayar brokoli yang dipasok oleh petani mitra dan telah disortasi sesuai dengan harga yang telah disepakati oleh kedua belah pihak.

Kesepakatan kontraktual antara CV. Yan's Fruits and Vegetabledengan ritel berupa bentuk kesepakatan tentang pembayaran dan kualitas komoditas sesuai dengan pesanan. Sistem pembayaran yang dilakukan oleh ritel dilakukan dengan cara membayar setelah dua minggu brokoli tersebut dikirimkan.

Sistem transaksi. Harga yang diberikan CV. Yan's Fruits and Vegetable kepada petani mitra untuk komoditas brokoli adalah Rp 20.000 per kg. Setelah dikemas, brokoli akan dipisahkan berdasarkan grade. Semua grade brokoli memiliki harga yang sama. Akan tetapi, perusahan tetap melakukan grading untuk memenuhi permintaan khusus dari suatu ritel demi menjaga jalinan kerjasama dan kepercayaan ritel. Harga jual brokoli dari perusahaan kepada ritel adalah Rp 34.000 per kg. Setelah memperoleh penentuan harga dari ritel, perusahaan baru dapat memberikan harga kepada petani. Rencana perubahan harga langsung diinformasikan kepada petani satu minggu sebelum perubahan harga ditetapkan. Pembayaran hasil panen petani dilakukan dua minggu setelah panen setelah dilakukan sortasi. Pembayaran yang dilakukan oleh supermarket dibayarkan setelah dua mnggu komoditas tersebut dikirimkan.

Sumber daya rantai pasok. Sumber daya rantai pasok merupakan segala hal yang digunakan untuk menghasilkan produk dan mengirimkannya kepada pelanggan (transformasi sumber daya). Sumber daya rantai pasok terdiri dari sumber daya fisik, sumber daya manusia, teknologi, dan permodalan. Peninjauan sumberdaya milik pelaku rantai pasok dilakukan untuk mengetahui potensi-potensi yang dapat mendukung upaya pengembangan rantai pasok.

Sumber daya fisik. Transportasi yang digunakan oleh CV. Yan's fruits and Vegetable untuk mengangkut brokoli ke ritel adalah mobil box yang dilengkapi dengan alat pendingin untuk mencegah kerusakan produk sebelum sampai ke tangan ritel atau konsumen. Kapasitas alat angkut adalah 25 kontainer per mobil. Sumber daya fisik lain yang dimiliki CV. Yan's fruits and Vegetable adalah bangunan kantor merangkap gudang pemasaran, peralatan penunjang kegiatan kantor seperti komputer, printer, mesin fax, telepon, dan alat tulis, satu mobil pick up untuk menjemput sayuran dari petani yang kebunnya jauh, dan 5 buah mobil box untuk mengantar sayuran ke ritel. Untuk sortasi dan pengemasan, perusahaan menggunakan pisau, gunting, plastik wrapping film ukuran besar, timbangan besar dan kecil, keranjang panen (kontainer), dan sarana penunjang lainnya.

Ritel memiliki sumber daya fisik berupa bangunan toko dan gudang penyimpanan (cool storage). Gudang penyimpanan berguna untuk menjaga kesegaran sayuran karena CV. Yan's fruits and Vegetable tidak setiap hari memasok sayuran, sehingga dapat menjaga kualitas sayuran.

Sumber daya teknologi. Pembibitan dilakukan di greenhouse karena pada tahap ini rawan serangan hama sehingga dibutuhkan tempat khusus. Sistem irigasi yang dilakukan pada pembenihan dengan sistem penyiraman dengan menggunakan sprinkle.

Teknologi yang digunakan oleh petani mitra pemasok brokoli sudah tepat guna, tetapi masih sederhana. Penerapan teknologi tepat guna terlihat dari bibit dan pupuk yang digunakan. Bibit yang digunakan merupakan bibit brokoli varietas bejo, sementara pupuknya sudah menggunakan pupuk organik diantaranya pupuk kandang dan kompos, tetapi masih menggunakan sedikit pupuk kimia. Produksi brokoli masih mengalami kendala cuaca yang tidak menentu dan serangan hama.

Teknologi yang sederhana juga masih diterapkan di CV. Yan's fruits and Vegetable. Hal ini dikarenakan sayuran yang dikirimkan oelh petani langsun dikemas dan dikirimkan kepada ritel tanpa penundaan. Untuk menjaga kesegaran sayuran selama pengiriman, perusahaan sudah mengandalkan cooler storage. 
Sumber daya manusia. Sumber daya manusia yang digunakan pada bidang budidaya brokoli adalah antara dua sampai lima orang tenaga kerja yang sebagian besar merupakan tenaga kerja dalam keluarga. Pekerjaannya mencakup persiapan lahan, penanaman, perawatan, pemanenan, dan penanganan pasca panen berupa sortasi dan distribusi ke gudang.

Sumber daya manusia yang digunakan di gudang pemasaran sebanyak tlima orang pegawai dengan gaji bulanan, 30 orang pegawai harian tetap, termasuk supir. Seluruh pekerja di gudang pemasaran berpartisipasi pada penanganan pasca panen mulai dari proses penurunan sayuran dari mobil pick up hingga sayuran didistribusikan ke ritel di wilayah Jakarta dan sekitarna.

Sumber daya modal. Pembiayaan khususnya di sektor pertanian masih cukup sulit karena pihak perbankan menilai pertanian merupakan sektor yang berisiko tinggi (high risk) dan tingkat turn over yang relatif rendah. Petani menggunakan modal sendiri dalam melakukan budidaya brokolidengan jumlah yang berneka ragam, tetapi petani sering meminjam modal dari sesama petani brokoli. Alasan petani tidak melakukan pinjaman modal ke lembaga keuangan karena sulitnya persyaratan yang diajukan oleh pihak bank dan kebanyakan petani tidak mempunyai agunan sebagai jaminan atas pinjamannya. Perusahaan membayar petani tepat waktu sehingga uang tersebut dapat digunakan petani untuk membiayai budidaya brokoli berikutnya.

\section{Proses Bisnis Rantai Pasok}

Hubungan proses bisnis rantai pasok. Pada rantai pasok brokoli hanya terdapat tiga siklus, yaitu procurement, replenishment, dan customer order. Siklus manufacturing tidak terdapat dalam rantai pasok ini karena tidak melibatkan anggota rantai pasok yang berperan sebagai pengolah langsung. Petani mitra hanya melakukan sortasi dan grading, begitu pula dengan CV. Yan's Fruits and Vegetable yang hanya melakukan pengemasan dan pelabelan. Siklus procurement dilakukan oleh ritel kepada CV. Yan's Fruits and Vegetable dan CV. Yan's Fruits and Vegetable kepada petani mitra untuk merespon permintaan konsumen. Pemesanan (pre-order) dilakukan melalui e-mail, pesan singkat, dan faximile. Siklus procurement termasuk dalam proses pull. Siklus replenishment dilakukan oleh ritel dan CV. Yan's Fruits and Vegetable dengan menambah jumlah pesanan dari jumlah pesanan sebenarnya, sebagai antisipasi jika terjadi pemesanan tambahan dari konsumen atau jika terjadi kerusakan pada produk. Siklus replenishment termasuk dalam proses push, dan siklus customer order dilakukan oleh konsumen dengan memesan secara langsung kepada pihak ritel.

Pola distribusi. Produk yang dialirkan dalam rantai pasok ini adalah brokoli. Brokoli yang telah dikemas merupakan produk akhir yang diterima konsumen akhir. Kualitas brokoli yang didistribusikan adalah kualitas super. Aliran produk dimulai dari petani melakukan panen saat umur dan fisik brokoli sudah memenuhi standar, lalu dilakukan sortasi dan grading. Brokoli yang dipanen petani adalah brokoli dengan berat 100-750 gram, bunga rapat dan berwarna hijau kebiruan, dan tidak busuk batang. Selanjutnya brokoli dikemas degan plastik kemasan $15 \mathrm{~kg}$ untuk diantar ke gudang pemasaran. Sampai di gudang pemasaran, brokoli akan langsung dijemur untuk menghilangkan embun, lalu disortasi lagi dengan memotong batang yang busuk dan menghilangkan hama yang masih menempel pada bunga, batang, dan daun brokoli, dikemas dengan roll film wrapping serta diberi label, ditimbang serta dibagikan ke dalam kontainer

Perencanaan kolaboratif. CV. Yan's Fruits and Vegetable melakukan perencanaan kolaboratif dengan para petani mitranya. Para konsumen memberikan informasi mengenai jumlah permintaan brokoli. CV. Yan's Fruits and Vegetable melakukan perencanaan dengan cara menargetkan sebanyak $500 \mathrm{~kg}$ brokoli per hari nya. Target pengiriman harian berdasarkan pada peramalan permintaan dua minggu ke depan. Sistem pemanenan tidak dilakukan secara bersama-sama oleh semua mitra tani, tetapi pada bagian kemitraan yang menentukan petani mana yang akan panen pada minggu tersebut. 
Yolandika, C dkk : Rantai Pasok Brokoli di Kecamatan Lembang Kabupaten Bandung Barat ...

Aspek resiko. Risiko yang diterima petani terutama adalah gagal panen yang disebabkan oleh keadaan alam, misalnya adanya hujan yang terus menerus di pagi hari maka brokoli akan membusuk. Saat ini risiko gagal panen sepenuhnya masih ditanggung oleh petani. Selain gagal panen, risiko yang lain adalah pengembalian hasil panen karena komoditas yang dihasilkan tidak memenuhi syarat yang ditetapkan oleh perusahaan.

Risiko yang diterima oleh CV. Yan's Fruits and Vegetable lebih banyak daripada yang diterima oleh petani. Sistem kemitraan menyebabkan perusahaan berkewajiban membeli semua hasil panen dari petani sesuai dengan harga yang telah disepakati. Jika keseluruhan petani memiliki produktivitas hasil yang baik, maka tidak menutup kemungkinan akan terjadi kelebihan hasil panen dari petani yang menyebabkan kelebihan persediaan. Akan tetapi hal ini sangat jarang terjadi, karena petani sendiri sudah memperkirakan hasil yang akan diperoleh.

Proses membangun kepercayaan. Kepercayaan antara CV. Yan's Fruits and Vegetable dengan petani mitra brokoli terbentuk karena telah mengenal satu sama lain. Perusahaan mengetahui kemampuan dan komitmen petani mitra brokoli, sementara petani mitra percaya perusahaan mampu memasarkan brokoli yang dihasilkannya dan mampu menjaga komitmen harga dengan petani. Perjanjian kerjasama kontraktual antara petani mitra dan perusahaan dilakukan secara lisan. Akan tetapi, belum ada pihak yang melanggar perjanjian kerjasama kontraktual tersebut.

Kepercayaan antara CV. Yan's Fruits and Vegetable dengan pihak ritel terjalin karena CV. Yan's Fruits and Vegetable mampu memenuhi permintaan brokoli secara berkelanjutan dan selalu menjaga kualitas dari brokoli yang dikirim. Mengenai kuantitas, pihak ritel dapat memahami keadaan perusahaan, dengan syarat perusahaan harus memberi kabar kepada ritel melalui e-mail satu minggu sebelum pengiriman, jika mereka tidak dapat memasok sayuran dalam kuantitas sesuai dengan order. Kepercayaan juga terlihat dari pertukaran informasi mengenai harga. Kepercayaan pihak ritel dan CV. Yan's Fruits and Vegetable terikat dengan kontrak tertulis, dimana isi dalam perjanjian kontraktual tersebut dapat berubah-ubah seiring dengan berjalannya kerjasama.

\section{KESIMPULAN}

Kondisi rantai pasok brokoli di Kecamatan Lembang Kabupaten Bandung Barat Berdaasarkan Pendekatan Food Supply Chain Networks yang dilihat dari sasaraan rantai pasok, struktur rantai pasok, entitas rantai pasok, manajemen rantai pasok, sumber daya rantai pasok, dan proses bisnis rantai pasok sudah terintegrasi dengan baik.

\section{SARAN}

Diharapkan pemerintah dapat memperhatikan proses pendiisitribusian sayuran yang ada di Jawa Barat. Selain itu, diharapkan pula bagi petani brokoli di Kecamatan Lembang, agar dapat lebih memperhatikan kualitas serta kuantitas dari produksi, melalui penerapan model usaha tani yang telah dianjurkan oleh kelompok usahatani setempat, sehingga dapat menghasilkan hasil yang diharapkan.

\section{UCAPAN TERIMA KASIH}

Ucapan terimakasih diberikan penulis kepada "Kementerian Pendidikan dan Kebudayaan Republik Indonesia" yang telah memberikan beasiswa pendidikan kepada penulis selama menempuh pendidikan di Institut Pertanian Bogor.

\section{DAFTAR PUSTAKA}

[BPS] Badan Pusat Statistik. 2015. Luas Panen dan Produksi Sayuran Indonesia. Jakarta (ID): Badan Pusat Statistik. 
Chopra S, Meindhl P. 2007. Supply Chain Management : Strategy, Planning, and Operation. New Jersey (US): Pearson.

Dahl CD, Hammond JW. 1977. Market and Price Analysis Agricultural Industries. New York (US): MC Graw-ill Book Company.

Eriksson PE. 2010. Improving Construction Supply Chain Collabroration and Performance: A Lean Construction Pilot Project. Journal of Supply ChainManagement. 15(5): 394 - 403.

George, PS, King GA. 1971. Consumer Demand Food Commodities in The United States with Projection for 1980. Giani (US): Foundation Mongograph.

Heyzer JH, Render B. 2001. Seventh Edition: Operation Management. New Jersey (US): Prenyice hall Inc. International Edition.

Indrajit RE, Djokopranoto RE. 2002. Konsep Manajemen Supply Chain Cara Baru Memandang Mata Rantai Penyediaan Barang. Jakarta (ID) : Grassindo.

Jacobs FR, Chase RB. 2011. Operations and Supply Chain Management. New York (US): McGraw-Hill.

Kohls RL, Uhl JN. 2002. Marketing of Agricutural Products. New York (US): Mc Millan Publishing Company.

Pujawan IN. 2005. Supply Chain Management. Surabaya (ID): GunaWijaya.

Van der Vorst JGAJ. 2006. Quantifying the Agri-Food Supply Chain. Amsterdam (NLD): Logistics and Operations Research Group, Wageningen University. 